\title{
Family history of hepatocellulcar carcinoma is not associated with its patients' prognosis after hepatectomy
}

\author{
Jia Huang ${ }^{1 \dagger}$, Yaojun Zhang ${ }^{2,3 \dagger}$, Meixian Chen ${ }^{2,3}$, Junting Huang ${ }^{2,3}, \mathrm{Li} \mathrm{Xu}^{2,3}$ and Minshan Chen ${ }^{2,3^{*}}$
}

\begin{abstract}
Background: Family history of liver cancer is a major risk factor for hepatocellular carcinoma (HCC). In this study, we investigated the prognosis of patients with HCC with or without family history.

Methods: Data for 1,313 patients who underwent hepatectomy as initial treatment for HCC between 2000 and 2008 at a tertiary cancer center hospital were retrieved from a prospective database. A positive family history was defined as a self-reported history of HCC in first-degree relatives. Clinicopathologic characteristics were compared by family history. Kaplan-Meier method and Cox proportional hazards regressions were applied for overall survival (OS) and disease-free survival (DFS).

Results: Of 1,313 patients, 169 patients (12.9\%) had first-degree relatives with a history of HCC. There were no significant differences between patients with or without family history in basic clinicopathologic characteristics. In either whole group or each stage according to the TNM staging system, first-degree family history was not associated with survival in all patients, hepatitis B virus-positive patients, as well as male patients. Multivariate analysis revealed that first-degree family history was not a prognostic factor, either for OS or DFS.
\end{abstract}

Conclusion: A first-degree family history of HCC is not associated with its patients' prognosis after hepatectomy.

Keywords: Hepatocellular carcinoma, Hepatectomy, TNM staging system, Family history, Prognosis

\section{Background}

Hepatocellular carcinoma (HCC) is the fifth most common cancer worldwide and the third most frequent cause of death due to cancer [1]. Although the majority of cases are still found in Asia and Africa, recent evidence has shown that both incidence and mortality rate of HCC are rising in North America and Europe [2-4]. More than $75 \%$ of cases worldwide and $85 \%$ of cases in developing countries have been attributed to hepatitis B virus (HBV) and hepatitis C virus (HCV), both of which increase the risk of $\mathrm{HCC}$ about 20-fold [5-8]. Other well-recognized risk factors for HCC include advanced age, male gender, heavy alcohol drinking, aflatoxin exposure, tobacco smoking, cirrhosis, and some

\footnotetext{
* Correspondence: Chminsh@mail.sysu.edu.cn

${ }^{\dagger}$ Equal contributors

${ }^{2}$ Department of Hepatobiliary Surgery, Sun Yat-sen University Cancer Center, 651 Dongfeng Road East, Guangzhou 510060, China

${ }^{3}$ State Key Laboratory of Oncology in South China, Sun Yat-sen University Cancer Center, Guangzhou 510060, China

Full list of author information is available at the end of the article
}

rare monogenic syndromes (for example, hemocromatosis, alpha1-antitrypsin deficiency, and porphyria cutanea tarda) [6-8]. Recent studies [5-8] demonstrated that a family history of liver cancer increases HCC risk, independent of $\mathrm{HBV} / \mathrm{HCV}$ infection status. The combination of family history of liver cancer and positive $\mathrm{HBV} / \mathrm{HCV}$ serum markers is associated with an elevated HCC risk of $>70$ fold [8].

In the past decades the association between family history and cancer survival has been studied in various kinds of cancers, including colorectal cancer $[9,10]$, gastric cancer [11], breast cancer [12], and so on. Most of them demonstrated that a positive family history was associated with improved survival. Since the effect of a positive family history of HCC on the survival remains unclear, we performed the present study to evaluate the effect of family history on the clinicopathologic characteristics and prognosis of patients who received hepatectomy as initial treatment for HCC in a Chinese population. 


\begin{tabular}{|c|c|c|c|}
\hline \multirow[t]{3}{*}{ Variables } & \multicolumn{3}{|l|}{ All $(n=1,313)$} \\
\hline & \multicolumn{3}{|c|}{ Family history } \\
\hline & $\begin{array}{l}\text { Positive } \\
(n=169)\end{array}$ & $\begin{array}{l}\text { Negative } \\
(n=1144)\end{array}$ & $P$ value \\
\hline Age $(>50 / \leq 50$ years $)$ & $54 / 115$ & $510 / 634$ & 0.101 \\
\hline Gender (M/F) & $145 / 24$ & $1002 / 142$ & 0.514 \\
\hline $\mathrm{ALT}(\mathrm{u} / \mathrm{L})$ & $45.7 \pm 38.7$ & $51.5 \pm 55.7$ & 0.192 \\
\hline ALB (g/L) & $42.0 \pm 6.8$ & $41.7 \pm 4.5$ & 0.497 \\
\hline TBIL (umol/L) & $16.7 \pm 9.7$ & $18.7 \pm 18.3$ & 0.168 \\
\hline $\mathrm{Cr}$ (umol/L) & $93.0 \pm 20.7$ & $92.2 \pm 28.2$ & 0.078 \\
\hline PT (s) & $13.3 \pm 1.2$ & $13.3 \pm 1.3$ & 0.644 \\
\hline PLT count $\left(\times 10^{9} / \mathrm{L}\right)$ & $181.9 \pm 91.8$ & $187.1 \pm 76.9$ & 0.837 \\
\hline $\operatorname{AFP}(\leq 400 />400 \mathrm{ng} / \mathrm{mL})$ & $98 / 71$ & $637 / 507$ & 0.573 \\
\hline HBV (positive/negative) & $153 / 16$ & $959 / 185$ & 0.220 \\
\hline Liver cirrhosis (Yes/No) & $149 / 20$ & $940 / 204$ & 0.302 \\
\hline Child Pugh (A/B) & $167 / 2$ & $1123 / 21$ & 0.546 \\
\hline Tumor size (cm) & $7.4 \pm 4.2$ & $7.3 \pm 4.1$ & 0.871 \\
\hline Tumor number $(1 />1)$ & $127 / 42$ & $867 / 277$ & 0.857 \\
\hline Major vascular invasion & 19 & 144 & 0.621 \\
\hline Micro vascular invasion & 19 & 125 & 0.902 \\
\hline Follow-up (months) & $41.6 \pm 32.8$ & $44.7 \pm 34.5$ & 0.269 \\
\hline & (range 2.0-136.0) & (range 2.0-142.0) & \\
\hline
\end{tabular}

AFP alpha-fetoprotein; $A L T$ alanine transferase; $A L B$ serum albumin; $C r$ creatinine; $H B V$ hepatitis B virus; PLT platelets; PT prothrombin time; TBIL total bilirubin.

\section{Methods}

Ethics statement

The research was approved by the institutional review board (IRB) of Sun Yat-sen University Cancer Center, and written informed consent was obtained from each patient involved in the study.

\section{Patients}

This is a retrospective study based on prospectively collected data at our hospital. Data on patients who underwent hepatectomy as initial treatment for HCC at the Department of Hepatobiliary Surgery, Sun Yat-Sen University Cancer Canter (Guangzhou, China) from 2000 to 2008 were retrieved from a prospective database. Only patients who met all of the following criteria were included: (1) no previous treatment for HCC before surgery; (2) histologic confirmation of HCC; (3) macroscopically completely resected, with a microscopically tumor-free margin proven by the pathology (R0 resection); (4) no lymph node or extrahepatic metastasis; (5) no history of other malignant disease; and (6) completed an interview about family history and health behavior. Since the current study aimed to analyze the prognostic factors for long-term survival, patients who died either perioperatively $<30$ days following surgery or during the original hospital stay if $>30$ days were excluded from this study.

Table 2 Overall and disease-free survival of the study population by family history and tumor stage

\begin{tabular}{|c|c|c|c|c|c|c|c|}
\hline \multirow[t]{2}{*}{ TMN } & \multirow[t]{2}{*}{ Family history } & \multirow[t]{2}{*}{$n$} & \multicolumn{4}{|c|}{ Overall survival } & \multirow[b]{2}{*}{$P$ value } \\
\hline & & & Median survival (months) & 1 year $(\%)$ & 3 years $(\%)$ & 5 years $(\%)$ & \\
\hline \multirow[t]{2}{*}{ All } & Positive & 169 & 43 & 79.3 & 54.7 & 43.5 & 0.511 \\
\hline & Negative & 1,144 & 47 & 79.2 & 55.5 & 45.8 & \\
\hline \multirow[t]{2}{*}{ | } & Positive & 87 & 79 & 87.4 & 71.0 & 58.9 & 0.282 \\
\hline & Negative & 623 & 123 & 89.7 & 71.0 & 58.9 & \\
\hline \multirow[t]{2}{*}{$\|$} & Positive & 21 & 32 & 81.0 & 44.2 & 36.8 & 0.441 \\
\hline & Negative & 146 & 53 & 75.3 & 55.9 & 48.6 & \\
\hline \multirow[t]{2}{*}{ III } & Positive & 61 & 22 & 67.7 & 34.7 & 24.8 & 0.550 \\
\hline & Negative & 375 & 20 & 63.2 & 29.9 & 23.0 & \\
\hline \multirow[t]{2}{*}{ TMN } & Family history & $n$ & \multicolumn{4}{|c|}{ Disease-free survival } & \\
\hline & & & Median survival (month) & 1 year $(\%)$ & 3 years (\%) & 5 years $(\%)$ & $P$ value \\
\hline \multirow[t]{2}{*}{ All } & Positive & 169 & 12 & 50.3 & 33.8 & 27.6 & 0.231 \\
\hline & Negative & 1,144 & 14 & 52.9 & 36.7 & 32.4 & \\
\hline \multirow[t]{2}{*}{ | } & Positive & 87 & 28 & 61.2 & 45.6 & 36.4 & 0.186 \\
\hline & Negative & 623 & 35 & 66.8 & 49.2 & 44.5 & \\
\hline \multirow[t]{2}{*}{$\|$} & Positive & 21 & 4 & 40.9 & 29.8 & 29.8 & 0.202 \\
\hline & Negative & 146 & 12 & 49.0 & 35.8 & 32.2 & \\
\hline \multirow[t]{2}{*}{ |II } & Positive & 61 & 7 & 38.7 & 18.7 & 15.0 & 0.337 \\
\hline & Negative & 375 & 5 & 31.5 & 16.2 & 12.2 & \\
\hline
\end{tabular}


All the preoperative parameters was recorded and evaluated as possible predictors of survivals including gender, age, HBV status, platelet count (PLT), prothrombin time (PT) alpha-fetoprotein (AFP), alanine transferase (ALT), total bilirubin level (TBIL), albumin (ALB), creatinine (Cr), liver function status, tumor size and number, and tumor thrombus. Liver functional reserve was also assessed using ChildPugh classification. HBV positive was defined as HBsAg (+).

\section{Family history assessment}

Family history of HCC was ascertained by selfreporting through an interview at the time of index case diagnosis. Cases with family history of HCC in a first-degree relative were recognized as those having at least one first-degree relative with HCC. Firstdegree relatives include parents, siblings, or offspring. Family history in second-degree relatives was not assessed in present analysis. No questions were asked about family size.
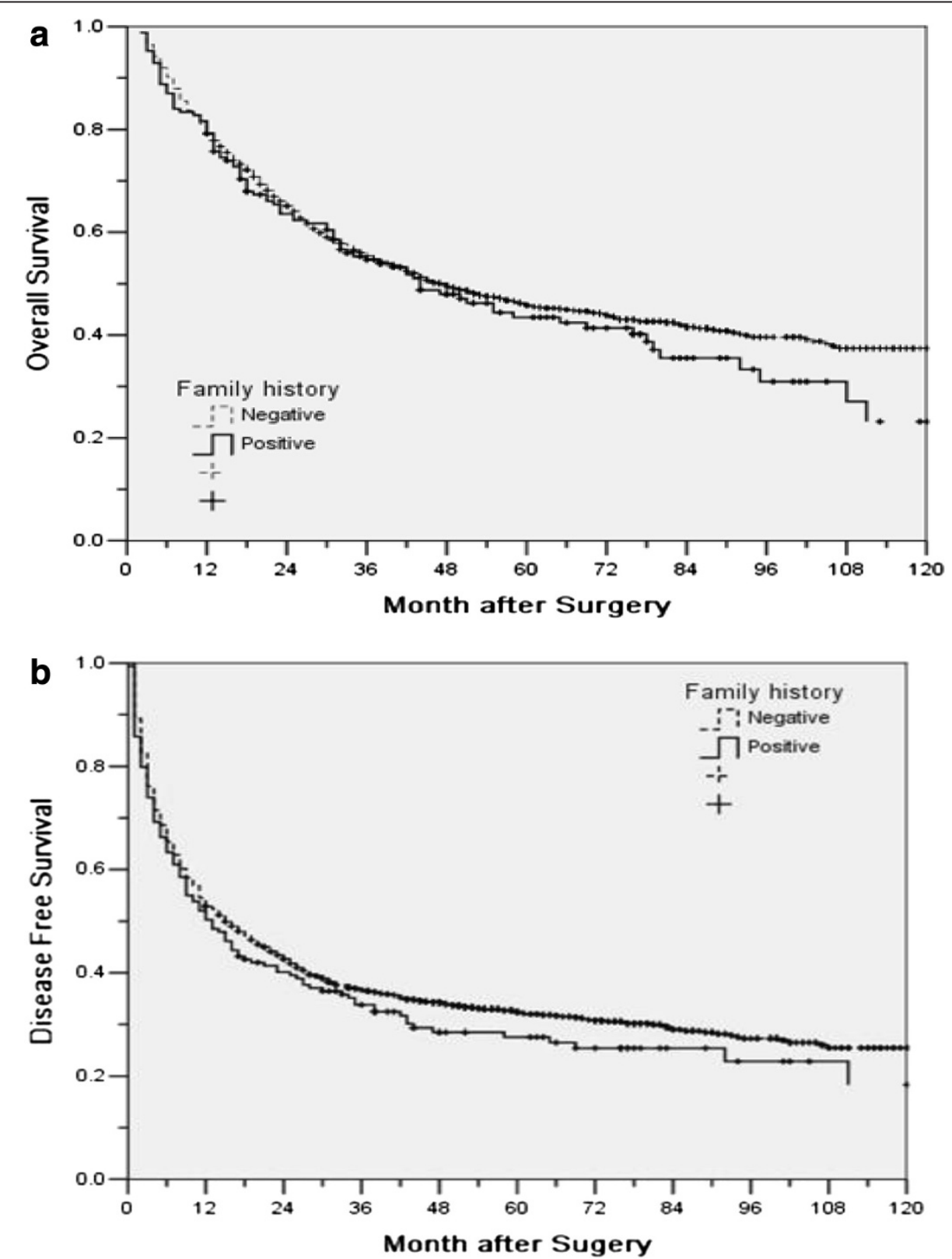

Figure 1 Overall (a) and disease-free survival (b) for patients with or without family history. 


\section{Technique of hepatectomy}

Hepatectomy was carried out by using the techniques we described previously [13]. In brief, hepatectomy was carried out under general anesthesia using a right subcostal incision with midline extension. Intraoperative ultrasonography was routinely performed to confirm resectability and to visualize major vascular structures. Pringle's maneuver was routinely used with a clamp/unclamp time of $10 / 5 \mathrm{~min}$. The liver parenchyma was divided with a clamp-crushing technique or ultrasonic dissector (CUSA) according to the surgeon's preference. Anatomic resection was our preferred surgical method in hepatic resection for multiple nodules in one segment or in neighboring segments. For anatomic resection, the hepatic parenchyma was transected at the intersegmental plane as described by Couinaud. For multiple bilobar nodules, anatomic resection was preferred for the main tumor, while satellite nodules were resected non-anatomically with intent for a negative resection margin. When an inadequate liver remnant was suspected, non-anatomic resection was performed with intent for a negative resection margin. Hemostasis on the raw liver surface was achieved with suturing and fibrin glue.

\section{Follow-up}

Patients were followed up every 3 months for the first 2 years, then every 6 months thereafter with physical examination, blood tests for AFP and liver function, and contrast abdominal computed tomography (CT). Chest radiography was done every 6 months to detect lung metastasis. When metastasis was suspected, CT chest, bone scintigraphy, positron emission tomography (PET), and biopsy if indicated were also performed to confirm metastasis and/or recurrence. The last follow-up date for patients still alive was in October 2012.

Causes of death and sites of recurrence were determined from death certificates, medical interviews, and radiological findings. Overall survival (OS) was defined as the interval between surgery and time of either death or last follow-up. Disease-free survival (DFS) was defined as the length of time after liver resection for HCC to detectable intrahepatic and/or extrahepatic recurrence. The treatment for recurrent tumors was determined by our multidisciplinary team (MDT) made up of surgeons, oncologists, radiologists, hepatologists, and pathologists.

\section{Statistical analyses}

The statistical analyses were performed using the SPSS 13.0 statistical software (SPSS Company, Chicago, IL, USA). The two groups were compared using student's t-test for continuous data and the Chi-square test for categorical data. The OS and DFS were calculated using the Kaplan-Meier method and compared using log-rank test. The prognostic factors in predicting OS and DFS

Table 3 Overall and disease-free survival of HBV positive patients by family history and tumor stage

\begin{tabular}{|c|c|c|c|c|c|c|c|}
\hline \multirow[t]{2}{*}{ TMN } & \multirow[t]{2}{*}{ Family history } & \multirow[t]{2}{*}{$n$} & \multicolumn{4}{|c|}{ Overall survival } & \multirow[b]{2}{*}{$P$ value } \\
\hline & & & Median survival (month) & 1 year (\%) & 3 years (\%) & 5 years (\%) & \\
\hline \multirow[t]{2}{*}{ All } & Positive & 153 & 43 & 78.4 & 53.8 & 41.6 & 0.241 \\
\hline & Negative & 959 & 46 & 79.1 & 54.9 & 44.7 & \\
\hline \multirow[t]{2}{*}{ । } & Positive & 77 & 79 & 85.7 & 72.5 & 58.6 & 0.371 \\
\hline & Negative & 529 & 105 & 90.2 & 71.0 & 57.5 & \\
\hline \multirow[t]{2}{*}{$\|$} & Positive & 19 & 31 & 78.9 & 37.4 & 29.9 & 0.286 \\
\hline & Negative & 115 & 48 & 73.0 & 53.8 & 46.6 & \\
\hline \multirow[t]{2}{*}{ III } & Positive & 57 & 22 & 68.4 & 32.3 & 21.7 & 0.536 \\
\hline & Negative & 315 & 19 & 62.9 & 27.8 & 22.1 & \\
\hline \multirow[t]{2}{*}{ TMN } & Family history & $n$ & \multicolumn{4}{|c|}{ Disease-free survival } & \\
\hline & & & Median survival (month) & 1 year (\%) & 3 years (\%) & 5 years (\%) & $P$ value \\
\hline \multirow[t]{2}{*}{ All } & Positive & 153 & 13 & 51.0 & 33.4 & 27.4 & 0.246 \\
\hline & Negative & 959 & 16 & 53.1 & 36.0 & 31.6 & \\
\hline \multirow[t]{2}{*}{ । } & Positive & 77 & 28 & 62.3 & 45.1 & 36.6 & 0.174 \\
\hline & Negative & 529 & 34 & 67.7 & 49.0 & 43.6 & \\
\hline \multirow[t]{2}{*}{$\|$} & Positive & 19 & 4 & 36.9 & 23.0 & 23.0 & 0.179 \\
\hline & Negative & 115 & 12 & 48.7 & 34.5 & 30.9 & \\
\hline \multirow[t]{2}{*}{ III } & Positive & 57 & 8 & 40.4 & 20.4 & 16.3 & 0.189 \\
\hline & Negative & 315 & 5 & 30.2 & 14.5 & 11.5 & \\
\hline
\end{tabular}


were assessed by multivariate Cox proportional hazards regression analysis. All covariates that affected survival at the $P<0.10$ level of significance in univariate analysis were included in a multivariate Cox proportional hazards model. Results were given as mean \pm SD. All statistical tests were two-sided, and a significant difference was considered when $P<0.05$.

\section{Results}

\section{Baseline characteristics}

A total of 1,427 patients with $\mathrm{HCC}$ who underwent hepatectomy as initial treatment were identified during the study period. Based on our inclusion criteria, 114 patients were excluded from this study, consisting of patients with lymph node metastasis $(n=11)$, positive resection margins ( $n=77,5.40 \%, 77 / 1,427)$, and those that died postoperatively ( $n=26$, mortality of $1.82 \%, 26 / 1,427)$.

Patients' baseline characteristics were summarized in Table 1. A total number of 1,313 patients were included in the study, including 169 patients $(12.9 \%, 169 / 1,313)$ had a family history of HCC. The demographic and clinicopathologic characteristics of patients with or without a family history of HCC were compared, and no significant difference was identified between these two groups.

\section{Effect of family history on survival}

The median follow-up period was 44 months (range 2.573.5 months). The 1-, 3-, and 5-year OS for all patients
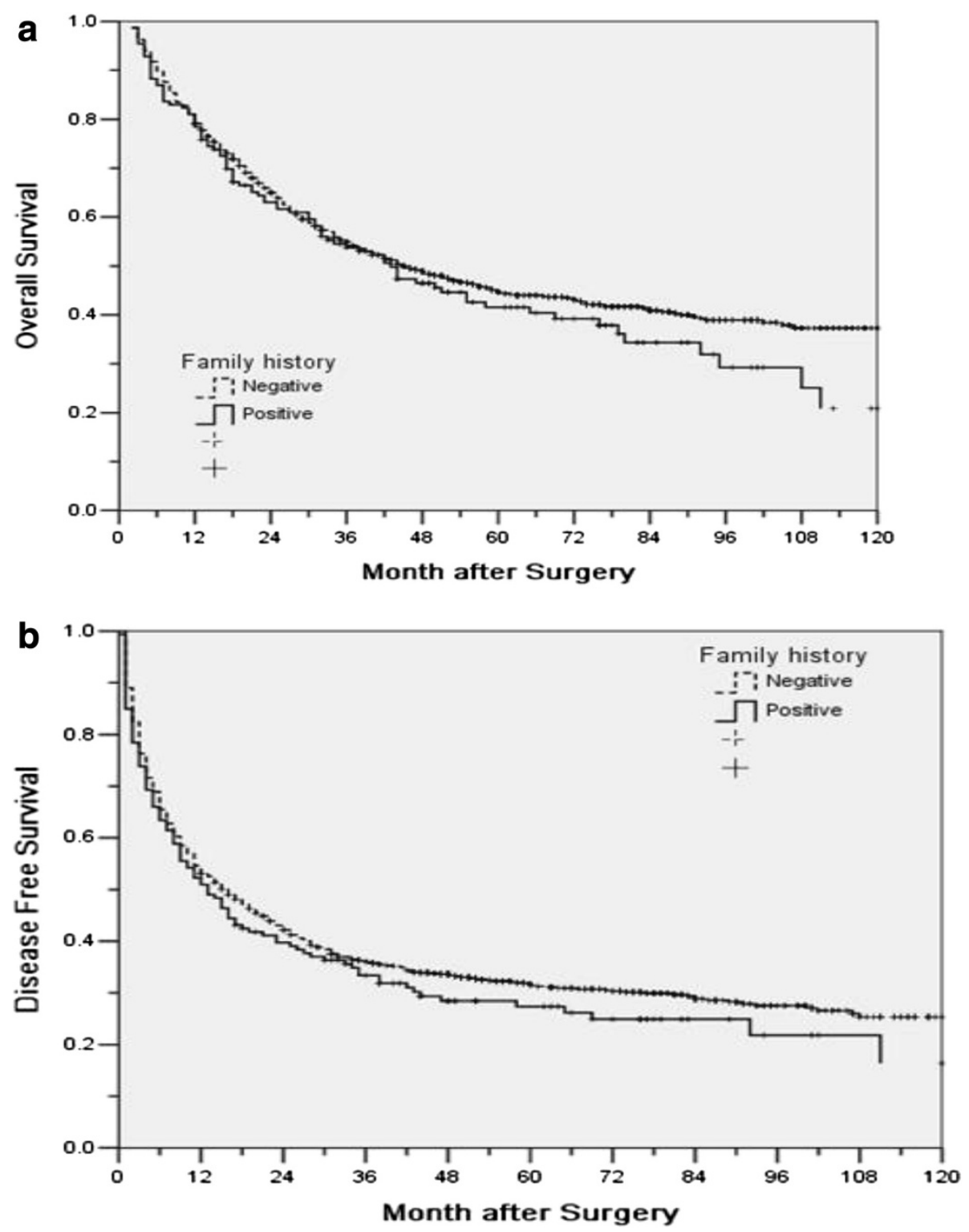

Figure 2 Overall (a) and disease-free survival (b) for HBV positive patients with or without family history. 
were $79.2 \%, 55.4 \%$, and $45.5 \%$, respectively, and the median OS was 47 months. The 1-, 3-, and 5-year DFS was $52.6 \%, 36.1 \%$, and $31.8 \%$, respectively, and the median DFS was 15 months.

Table 2 summarized the OS and DFS of patients with or without a family history of HCC for all patients and subgroups according to TNM-7. For either OS or DFS, there was no significant difference in all patients nor in subgroups (Table 2, Figure 1).

Since the synergism between HBV and a family history of HCC was noted by several studies, the OS and DFS of HBV positive patients with or without a family history of HCC were compared in Table 3. Similarly, for either OS or DFS, there was no significant difference in all patients nor in subgroups (Table 3, Figure 2).

It was also reported that a family history of HCC was only a risk factor in men but not women. The OS and
DFS of male patients with or without a family history of HCC were compared in Figure 3. Similarly, there was no significant difference in either OS or in DFS $(P=0.313$ and $P=0.282$, respectively, Figure 3 ).

\section{Prognostic factors}

All factors listed in Table 1 were included in univariate analysis and the covariates that affected survival at the $P<0.10$ level of significance in univariate analysis were included in a multivariate Cox proportional hazards model. Multivariate analysis showed that major vascular invasion (HR 2.624, 95\% CI 2.149-3.203, $P<0.001$ ), tumor size (HR 1.670, 95\% CI 1.405-1.986, $P<0.001$ ), tumor number (HR 1.569, 95\% CI 1.333-1.846, $P<0.001$ ), PT (HR 1.424, 95\% CI 1.217-1.666, $P<0.001$ ), ALB (HR 1.363, 95\% CI 1.005-1.848, $P=0.046$ ), PLT (HR 1.287, 95\% CI $1.034-1.602, P=0.024)$, and AFP (HR 1.179, 95\% CI
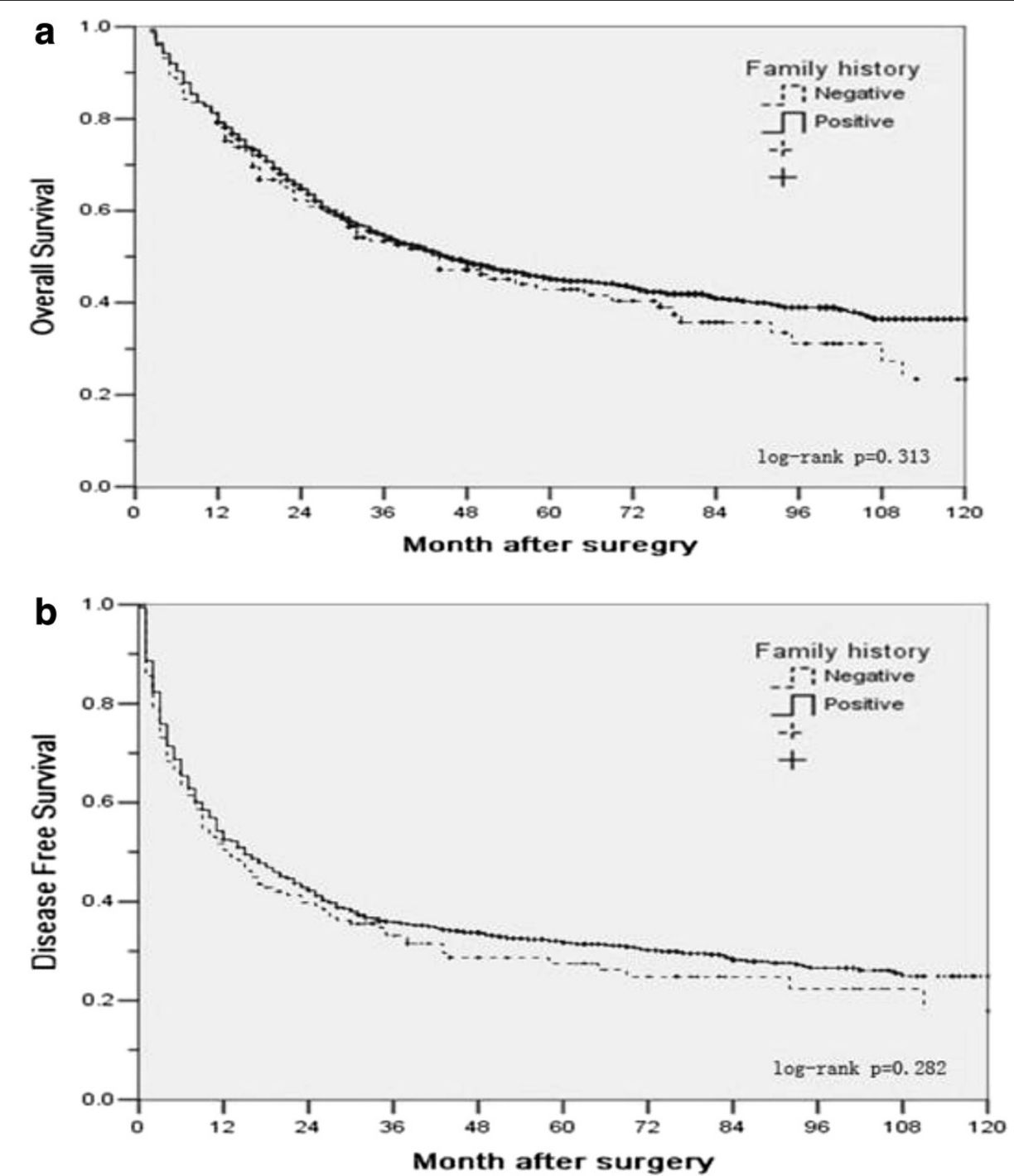

Figure 3 Overall (a) and disease-free survival (b) for male patients with or without family history. 
1.011-1.375, $P=0.035)$ were significant prognostic factors for OS (Table 4).

For DFS, multivariate analysis showed that major vascular invasion (HR 2.456, 95\% CI 2.036-2.962, $P<0.001$ ), tumor number (HR 1.617, 95\% CI 1.397-1.872, $P<0.001$ ), tumor size (HR 1.541, 95\% CI 1.326-1.789, $P<0.001$ ), micro vascular invasion (HR 1.338, 95\% CI 1.082-1.655, $P=0.007$ ), and PT (HR 1.253, 95\% CI 1.092-1.438, $P=0.001$ ) were significant prognostic factors (Table 4).

Family history was not a significant prognostic factor for either OS or DFS.

\section{Discussion}

Numerous studies [8,14-24] have demonstrated that a positive family history of liver cancer increases the risk of developing HCC. However, no previous studies have examined the influence of family history of liver cancer on subsequent outcomes in patients with established cancer. In this study, for the first time, we investigated the effect of family history on the clinicopathologic characteristics and prognosis of HCC. Our results showed that there was no significant difference in clinicopathologic characteristics and prognosis for patients with or without family history of $\mathrm{HCC}$, either in all patients or in subgroups.

This study is based on family history as reported by patients, and only cases with a family history of HCC in first-degree relatives were included and analyzed. In the Connecticut Family Health Study [25], reports from firstdegree relatives were more accurate than those from second-degree relatives, with positive predictive values between $78 \%$ and $80 \%$ for lung and breast cancer.

Table 4 Multivariate analysis of prognostic factors for overall and disease-free survival

\begin{tabular}{llll}
\hline Variables & \multicolumn{3}{l}{ Overall survival } \\
\cline { 2 - 4 } & HR & $\mathbf{9 5 . 0 \% ~ C l}$ & $\boldsymbol{P}$ value \\
\hline ALB $(>35 / \leq 35 \mathrm{~g} / \mathrm{L})$ & 1.363 & $1.005-1.848$ & 0.046 \\
PT $(>15 / \leq 15 \mathrm{~s})$ & 1.424 & $1.217-1.666$ & $<0.001$ \\
PLT count $\left(>100 / \leq 100 \times 10^{9} / \mathrm{L}\right)$ & 1.287 & $1.034-1.602$ & 0.024 \\
AFP $(\leq 400 />400 \mathrm{ng} / \mathrm{mL})$ & 1.179 & $1.011-1.375$ & 0.035 \\
Tumor size $(>5 / \leq 5 \mathrm{~cm})$ & 1.670 & $1.405-1.986$ & $<0.001$ \\
Tumor number $(1 />1)$ & 1.569 & $1.333-1.846$ & $<0.001$ \\
Major vascular invasion & 2.624 & $2.149-3.203$ & $<0.001$ \\
Variables & Disease-free survival & \\
\cline { 2 - 4 } & $\mathbf{H R}$ & $\mathbf{9 5 . 0 \%} \mathrm{Cl}$ & $\boldsymbol{P}$ value \\
PT (>15 / $\leq 15 \mathrm{~s})$ & 1.253 & $1.092-1.438$ & 0.001 \\
Tumor size $(>5 / \leq 5 \mathrm{~cm})$ & 1.541 & $1.326-1.789$ & $<0.001$ \\
Tumor number $(1 />1)$ & 1.617 & $1.397-1.872$ & $<0.001$ \\
Major vascular invasion & 2.456 & $2.036-2.962$ & $<0.001$ \\
Micro vascular invasion & 1.338 & $1.082-1.655$ & 0.007 \\
\hline
\end{tabular}

AFP alpha-fetoprotein; $A L B$ serum albumin; PLT platelets; $P T$ prothrombin time.
Furthermore, several studies $[5,8,14,24]$ have shown that only the family history of HCC in first-degree relatives increases the risk of developing $\mathrm{HCC}$, but not second-degree relatives. Thus, we considered only firstdegree relatives and second-degree relatives were not assessed in this study. We observed that 169 of the 1,313 patients $(12.9 \%)$ had a family history of HCC in firstdegree relatives. Our results were similar to those previous epidemiologic studies from Asian, USA, and European populations. Yu et al. [13] from China demonstrated that $17.5 \%$ of 553 patients reported having first-degree family members with HCC. Hassan et al. [8] from the USA observed that $6.1 \%$ of the 347 patients with HCC reported having first-degree family members with liver cancer. In a case-control study in Italy [24], 37 of 284 HCC patients (13.0\%) reported having firstdegree relatives with liver cancer.

Family history of the disease was found to be associated with improved survival in some kinds of cancers [9-12], including colon cancer, breast cancer, and so on. However there was some controversy in regards to gastric cancer. Han et al. [11] and Palli et al. [26] reported that a positive family history of gastric cancer in first-degree relatives was associated with a decreased risk of death and recurrence in patients after adjustments for known prognostic factors. However, a report from Japan [27] found that a family history negatively affected survival among gastric cancer patients. In Taiwan [28], the survival curve of patients with a positive family history was similar to that of patients without a family history. In our study, the impact of family history of HCC on both OS and DFS were analyzed in all patients and in subgroups according to TNM-7 stage. However, no significant difference was identified in patients with or without family history of HCC in either OS or DFS, in all patients or in subgroups.

The synergism between $\mathrm{HBV} / \mathrm{HCV}$ and a family history of HCC was noted by several studies [5,8,14,24]. Turati et al. [24] reported that the combination of family history of liver cancer and HBV/HCV serum markers is associated to a $>70$-fold elevated HCC risk. The prognosis of HBVpositive patients with or without a family history was compared in our study. Similarly, there was no significant difference in either OS or DFS, in all patients or in subgroups. Only a few patients $(9.5 \%, 16 / 169)$ with a family history were $\mathrm{HBV}$-negative, the survival of $\mathrm{HBV}$-negative patients with or without a family history cannot be analyzed in the present study.

Hassan et al. [8] observed that family history of liver cancer was only a risk factor for HCC in men but not in women. Similar results were also shown in a prospective longitudinal 90,000-person cohort study in China [14] and a case-control study from Italy [15]. But Turati et al. [24] and two Japanese studies [20,21] observed a nonsignificantly stronger association between HCC risk and 
family history of liver cancer for men. The OS and DFS of male patients with or without a family history of HCC were also compared in current study. However, no significant difference was identified either in OS or in DFS.

Several limitations of this study require commenting. First, as we relied on self-reported family history, misclassification of family history status may be possible. However, prior studies [25,29] have demonstrated such data to be reliable. Moreover, because the data on family history were collected at study baseline before treatment, any errors in recall would have attenuated rather than exaggerated a true association with patient outcome. Second, we did not collect information regarding number of siblings, and the likelihood of having a family history of the disease may vary according to the number of siblings at risk for the disease. However, it is unlikely that family size independently affects survival. Another limitation is the lack of information on family history of chronic hepatitis, cirrhosis, and other inherited diseases such as genetic hemochromatosis and alpha-1-antitrypsin deficiency, which may be related to HCC risk and prognosis [30-32]. Third, because our study was based on a database in a single tertiary cancer center hospital and all patients received hepatectomy as initial treatment, our results may not be generalizable to a larger population of patients with HCC, or patients treated with other methods including transcather artery chemoembolization, local ablation therapy, systemic chemotherapy, and so on. However, the rate of family history in this cohort is similar to the general population of patients with HCC.

Finally, we cannot completely exclude the possibility that patients with a family history may experience an earlier detection of malignancy. However, the effect of family history persisted after adjusting for other patient and disease characteristics associated with cancer recurrence or survival. Additionally, administration of treatment, therapies for recurrence disease, and follow-up care were reasonably uniform among all participants. Moreover, the association between family history and survival remained largely unchanged across the TNM stage as well as HBV status.

Studies suggested the importance of genetic contributions to the development of HCC. However, the relationship between family history and outcome is likely to be complex and may be influenced by a confluence of genetic and environmental factors [33-35]. We considered whether shared environmental or lifestyle factors might contribute to our findings. Further investigation to explore the relationship between family history and these factors is required.

\section{Conclusion}

Our results showed that there was no significant difference in clinicopathologic characteristics and prognosis for patients with HCC after hepatectomy with or without family history of HCC, either in all patients or in subgroups.

\section{Competing interests}

The authors declare that they have no competing interests.

\section{Authors' contributions}

$\mathrm{JH}$ and $\mathrm{YZ}$ carried out the molecular genetic studies, participated in the sequence alignment and drafted the manuscript. JH, YZ, MC, JH, and MC participated in the design of the study and performed the statistical analysis. LX and MC conceived of the study, and participated in its design and coordination and helped to draft the manuscript. All authors read and approved the final manuscript.

\section{Author details}

'Department of Obstetrics and Gynaecology, First Affiliated Hospital of Sun Yat-sen University, 58 Zhongshan Road Second, Guangzhou 510089, China. ${ }^{2}$ Department of Hepatobiliary Surgery, Sun Yat-sen University Cancer Center, 651 Dongfeng Road East, Guangzhou 510060, China. ${ }^{3}$ State Key Laboratory of Oncology in South China, Sun Yat-sen University Cancer Center, Guangzhou 510060, China.

Received: 25 July 2013 Accepted: 30 September 2013 Published: 18 October 2013

\section{References}

1. Jemal A, Bray F, Center MM, Ferlay J, Ward E, Forman D: Global cancer statistics. CA Cancer J Clin 2011, 61:69-90.

2. Kew MC: Hepatocellular carcinoma in developing countries: prevention, diagnosis and treatment. World J Hepatol 2012, 4:99-104.

3. Lodato F, Mazzella G, Festi D, Azzaroli F, Colecchia A, Roda E: Hepatocellular carcinoma prevention: a worldwide emergence between the opulence of developed countries and the economic constraints of developing nations. World J Gastroenterol 2006, 12:7239-7249.

4. Bruix J, Llovet JM: Major achievements in hepatocellular carcinoma. Lancet 2009, 373:614-616.

5. Mazzanti R, Gramantieri L, Bolondi L: Hepatocellular carcinoma: epidemiology and clinical aspects. Mol Aspects Med 2008, 29:130-143.

6. Stuver S, Trichopoulos D: Cancer of the liver and biliary tract. In Cancer Epidemiology. 2nd edition. Edited by Adami H-O, Hunter D, Trichpoulos D. New York: Oxford Universiy Press; 2008:308-332.

7. Marrero JA, Fontana RJ, Fu S, Conjeevaram HS, Su GL, Lok AS: Alcohol, tobacco and obesity are synergistic risk factors for hepatocellular carcinoma. J Hepatol 2005, 42:218-224.

8. Hassan MM, Spitz MR, Thomas MB, Curley SA, Patt YZ, Vauthey JN, Glover KY, Kaseb A, Lozano RD, El-Deeb AS, Nguyen NT, Wei SH, Chan W, Abbruzzese JL, Li D: The association of family history of liver cancer with hepatocellular carcinoma: a case-control study in the United States. J Hepatol 2009, 50:334-341.

9. Chan JA, Meyerhardt JA, Niedzwiecki D, Hollis D, Saltz LB, Mayer RJ, Thomas J, Schaefer P, Whittom R, Hantel A, Goldberg RM, Warren RS, Bertagnolli M, Fuchs CS: Association of family history with cancer recurrence and survival among patients with stage III colon cancer. JAMA 2008, 299:2515-2523.

10. Zell JA, Honda J, Ziogas A, Anton-Culver H: Survival after colorectal cancer diagnosis is associated with colorectal cancer family history. Cancer Epidemiol Biomarkers Prev 2008, 17:3134-3140.

11. Han MA, Oh MG, Choi IJ, Park SR, Ryu KW, Nam BH, Cho SJ, Kim CG, Lee JH, Kim YW: Association of family history with cancer recurrence and survival in patients with gastric cancer. J Clin Oncol 2012, 30:701-708.

12. Thalib L, Wedrén S, Granath F, Adami HO, Rydh B, Magnusson C, Hall P: Breast cancer prognosis in relation to family history of breast and ovarian cancer. Br J Cancer 2004, 90:1378-1381.

13. Chen MS, Li JQ, Zheng Y, Guo RP, Liang HH, Zhang YQ, Lin XJ, Lau WY: A prospective randomized trial comparing percutaneous local ablative therapy and partial hepatectomy for small hepatocellular carcinoma. Ann Surg 2000, 243:321-328.

14. Yu MW, Chang HC, Liaw YF, Lin SM, Lee SD, Liu CJ, Chen PJ, Hsiao TJ, Lee PH, Chen CJ: Familial risk of hepatocellular carcinoma among chronic hepatitis B carriers and their relatives. J Nat/ Cancer Inst 2000, 92:1159-1164. 
15. Donato F, Gelatti U, Chiesa R, Albertini A, Bucella E, Boffetta P, Tagger A, Ribero ML, Portera G, Fasola M, Nardi G: A case-control study on family history of liver cancer as a risk factor for hepatocellular carcinoma in North Italy. Brescia HCC Study Cancer Causes Control 1999, 10:417-421.

16. Huang YS, Chern HD, Wu JC, Chao Y, Huang YH, Chang FY, Lee SD: Polymorphism of the $\mathrm{N}$-acetyltransferase 2 gene, red meat intake, and the susceptibility of hepatocellular carcinoma. Am J Gastroenterol 2003, 98:1417-1422.

17. London WT, Evans AA, McGlynn K, Buetow K, An P, Gao L, Lustbader E,

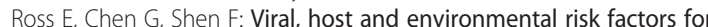
hepatocellular carcinoma: a prospective study in Haimen City. China Intervirol 1995, 38:155-161.

18. Yu MW, Yang SY, Chiu YH, Chiang YC, Liaw YF, Chen CJ: A p53 genetic polymorphism as a modulator of hepatocellular carcinoma risk in relation to chronic liver disease, familial tendency, and cigarette smoking in hepatitis B carriers. Hepatology 1999, 29:697-702

19. Liu TT, Fang $Y$, Xiong $H$, Chen TY, Ni ZP, Luo JF, Zhao NQ, Shen XZ: A case-control study of the relationship between hepatitis $B$ virus DNA level and risk of hepatocellular carcinoma in Qidong, China. World Gastroenterol 2008, 14:3059-3063.

20. Tanaka K, Hirohata T, Takeshita S, Hirohata I, Koga S, Sugimachi K, Kanematsu T, Ohryohji $\mathrm{F}$, Ishibashi $\mathrm{H}$ : Hepatitis B virus, cigarette smoking and alcohol consumption in the development of hepatocellular carcinoma: a case-control study in Fukuoka, Japan. Int J Cancer 1992, 51:509-514.

21. Tsukuma H, Hiyama T, Oshima A, Sobue T, Fujimoto I, Kasugai H, Kojima J, Sasaki Y, Imaoka S, Horiuchi N, Okuda S: A case-control study of hepatocellular carcinoma in Osaka, Japan. Int J Cancer 1990, 45:231-236.

22. Chen CJ, Liang KY, Chang AS, Chang YC, Lu SN, Liaw YF, Chang WY, Sheen MC, Lin TM: Effects of hepatitis B virus, alcohol drinking, cigarette smoking and familial tendency on hepatocellular carcinoma. Hepatology 1991, 13:398-406.

23. Fernandez E, La Vecchia C, D'Avanzo B, Negri E, Franceschi S: Family history and the risk of liver, gallbladder, and pancreatic cancer. Cancer Epidemiol Biomarkers Prev 1994, 3:209-212.

24. Turati F, Edefonti V, Talamini R, Ferraroni M, Malvezzi M, Bravi F, Franceschi S, Montella M, Polesel J, Zucchetto A, La Vecchia C, Negri E, Decarli A: Family history of liver cancer and hepatocellular carcinoma. Hepatology 2012, 55:1416-1425.

25. Mai PL, Garceau AO, Graubard BI, Dunn M, McNeel TS, Gonsalves L, Gail MH, Greene $M H$, Willis GB, Wideroff L: Confirmation of family cancer history reported in a population-based survey. J Natl Cancer Inst 2011, 103:788-797.

26. Palli D, Russo A, Saieva C, Salvini S, Amorosi A, Decarli A: Dietary and familial determinants of 10-year survival among patients with gastric carcinoma. Cancer 2000, 89:1205-1213.

27. Yatsuya H, Toyoshima H, Mizoue T, Kondo T, Tamakoshi K, Hori Y, Tokui N, Hoshiyama Y, Kikuchi S, Sakata K, Hayakawa N, Tamakoshi A, Ohno Y, Yoshimura T: Family history and the risk of stomach cancer death in Japan: Differences by age and gender. Int J Cancer 2002, 97:688-694.

28. Lee WJ, Hong RL, Lai IR, Chen CN, Lee PH, Huang MT: Clinicopathologic characteristics and prognoses of gastric cancer in patients with a positive familial history of cancer. J Clin Gastroenterol 2003, 36:30-33.

29. Kerber RA, Slattery ML: Comparison of self-reported and database-linked family history of cancer data in a case-control study. Am J Epidemiol 1997, 146:244-248.

30. Bruix J, Sherman M: Management of hepatocellular carcinoma. Hepatology 2005, 42:1208-1236

31. Bruix J, Llovet JM: Prognostic prediction and treatment strategy in hepatocellular carcinoma. Hepatology 2002, 35:519-524.

32. Shi M, Guo RP, Lin XJ, Zhang YQ, Chen MS, Zhang CQ, Wan Lau Y, Li JQ: Partial hepatectomy with wide versus narrow resection margin for solitary hepatocellular carcinoma: a prospective randomized trial. Ann Surg 2007, 245:36-43.

33. Volk ML, Lok AS: Is family history of liver cancer a risk factor for hepatocellular carcinoma? J Hepatol 2009, 50:247-248.
34. Zhu ZZ, Cong WM, Liu SF, Xian ZH, Wu WQ, Wu MC, Gao B, Hou LF, Zhu GS: A p53 polymorphism modifies the risk of hepatocellular carcinoma among non-carriers but not carriers of chronic hepatitis B virus infection. Cancer Lett 2005, 229:77-83.

35. Yu MW, Yang YC, Yang SY, Chang HC, Liaw YF, Lin SM, Liu CJ, Lee SD, Lin $\mathrm{CL}$, Chen PJ, Lin SC, Chen CJ: Androgen receptor exon 1 CAG repeat length and risk of hepatocellular carcinoma in women. Hepatology 2002, 36:156-163

doi:10.1186/1477-7819-11-280

Cite this article as: Huang et al:: Family history of hepatocellulcar carcinoma is not associated with its patients' prognosis after hepatectomy. World Journal of Surgical Oncology 2013 11:280.

\section{Submit your next manuscript to BioMed Central and take full advantage of:}

- Convenient online submission

- Thorough peer review

- No space constraints or color figure charges

- Immediate publication on acceptance

- Inclusion in PubMed, CAS, Scopus and Google Scholar

- Research which is freely available for redistribution

Submit your manuscript at www.biomedcentral.com/submit
C BioMed Central 